\title{
OPTIMASI PROPORSI CAMPURAN POLIVINIL PIROLIDON DAN AVICEL PH 101 DALAM FORMULASI TABLET ASAM MEFENAMAT SECARA SIMPLEX LATTICE DESIGN
}

\section{OPTIMIZATION OF PROPORTION OF MIXED POLYVINYL PYROLIDON (PVP) AND AVICEL PH 101 IN THE FORMULATION OF MEFENAMIC ACID TABLETS BY SLD (SIMPLEX LATTICE DESIGN)}

\author{
Dian Puspitasari ${ }^{1}$, Ilham Kuncahyo ${ }^{2}$, \\ dianpuspitasari2104@gmail.com \\ ${ }^{1}$ Program Studi S1 Farmasi, STIKES Nasional, Surakarta \\ ${ }^{2}$ Fakultas Farmasi, Universitas Setia Budi, Surakarta
}

\begin{abstract}
Abstrak
Asam mefenamat digunakan sebagai obat analgetik dan anti inflamasi non steroid. Masalah yang sering terjadi dalam proses penabletannya adalah asam mefenamat cenderung melekat pada permukaan stempel dan matris mesin tablet sehingga sering mengalami sticking dan secara berkelanjutan menyebabkan proses capping. Permasalahan lainnya adalah asam mefenamat mempunyai sifat hidrofobic dan kelarutan yang kecil sehingga disolusinya menjadi masalah. Kombinasi Avicel PH101 dan PVP diharapkan dapat memperbaiki permasalahan tersebut diatas, sehingga dapat diperoleh tablet asam mefenamat yang berkarakteristik baik.

Penelitian ini bertujuan untuk mendapatkan formula optimum campuran Avicel PH101 dan PVP dalam pembuatan tablet asam mefenamat secara granulasi basah menggunakan metode simplex lattice design (SLD) dengan dua komponen yaitu: Avicel PH101 (A) dan PVP (B). Tiga formula tablet asam mefenamat (F1 $(100 \% A)$, F2 (50\%A:50\%B), F3 (100\%B)) dibuat secara granulasi basah. Granul diuji waktu alir, kompaktibilitas dan dissolusi, sehingga didapatkan persamaan SLD. Persamaan tersebut digunakan untuk menentukan formula optimum yakni formula tablet dengan respon total sifat fisik granul yang paling optimum.

Hasil penelitian menunjukkan campuran Avicel PH 101 30\% - PVP 70\% memberikan hasil yang optimal pada sifat fisik granul dan tablet asam mefenamat yang dihasilkan memenuhi uji sifat fisik tablet.
\end{abstract}

Kata Kunci : asam mefenamat, avicel PH101, PVP, simplex lattice design

\begin{abstract}
Mefenamic acid is used as an analgesic and non-steroidal anti-inflammatory drugs. The problem that often occurs in the process of compressing is that mefenamic acid tends to stick on the surface of punch and die-compressing machine, so that it often experiences sticking and within a sustainable manner can cause capping process. The other problems of Mefenamic acid are hydrophobic and having low solubility, so that the dissolution becomes a problem. The combination of Avicel PH101 and PVP is expected to fix the problems, so that well-qualified Mefenamic acid tablets can be obtained.

This study was aimed at obtaining the optimum formula of mixed Avicel PH101 and PVP in the manufacture of mefenamic acid tablets by wet granulation, based on the method of simplex lattice design (SLD) with two components, namely: Avicel PH101 (A) and PVP (B). Three formulas of mefenamic acid tablets (F1 (100\% $A), F 2(50 \% A: 50 \%$ B), F3 $(100 \% B))$ are made by wet granulation. The granules are tested for the fluidity, compactibility and dissolution. The result is to obtain SLD
\end{abstract}


equation. The equation is used to determine the optimum formula which is the formula with the total response of the most optimal physical properties of granules.

The result of the experiment shows that optimum formula was obtained from Avicel PH 101 30\% - PVP 70\% mixture at granules' physical properties, and the obtained tablets of Mefenamic acid fulfills tablet physical property test.

Keywords : mefenamic acid, Avicel PH101, PVP, simplex lattice design

\section{Pendahuluan}

Asam mefenamat digunakan sebagai obat analgetik dan anti inflamasi non steroid yang tersedia dalam sediaan tablet dosis besar dengan pelepasan segera. Dalam proses penabletan, asam mefenamat cenderung melengkat pada permukaan stempel dan matris mesin tablet sehingga sering mengalami sticking dan secara berkelanjutan menyebabkan proses capping. Karena dosisnya yang besar tersebut, maka sering menjadi masalah dalam formulasi dan berpengaruh besar pada karakteristik kompresi granulnya dan sifat-sifat tablet yang dihasilkan (Adam, dkk., 2000).

Permasalahan lainnya adalah asam mefenamat mempunyai sifat hidrofobisitas dan kelarutan yang kecil sehingga disolusinya menjadi masalah (Adam, dkk., 2000).

Bahan pengikat yang digunakan dalam penelitian ini adalah Polivinilpirolidon (PVP). PVP dipilih sebagai bahan pengikat dikarenakan sifatnya yang komptibel dengan berbagai macam eksipien farmasetis dan juga non toksik (Kibbe, 2009). Kelebihan lain yang dimiliki PVP adalah kemampuan untuk larut dalam pelarut polar maupun non polar sehingga lebih memudahkan dalam pemilihan pelarut yang sesuai untuk metode granulasi basah (Foltmann dan Quadir, 2008). Oleh karena sifat kelarutan yang dimiliki PVP inilah diharapkan PVP dapat digunakan sebagai bahan pengikat tablet asam mefenamat dan sekaligus dapat memperbaiki pelepasan zat aktifnya (disolusi).

Avicel PH 101 yang dikenal juga sebagai selulosa mikrokristal merupakan eksipien yang sering digunakan dalam pembuatan tablet dengan granulasi basah. Selulosa mikrokristal dibuat dengan cara hidrolisis terkontrol alfa selulosa, suatu pulp dari tumbuhan yang berserat dengan larutan asam mineral encer (Rowe, et al., 2009). Avicel bersifat unik yaitu dapat digunakan sebagai bahan pengisi dan bahan penghancur karena memberikan kohesi yang kompak memiliki kompresibiltas yang sangat baik (Goeswin, 2008: 86 ). Karena sifat kompresibilitas yang baik ini diharapkan mampu mengatasi terjadinya capping pada proses pembuatan tablet asam mefenamat.

Untuk mengatasi permasalah-an yang banyak muncul pada proses pembuatan tablet asam mefenamat, maka perlu dilakukan penelitian tentang optimalisasi proporsi campuran bahan pembantu PVP sebagai bahan pengikat dan Avicel PH 101 sebagai bahan penghancur dalam formulasinya.

Upaya pencarian formula optimum tersebut dilakukan dengan simplex lattice design. Metode simplex lattice design merupakan salah satu metode untuk mencari formula optimum suatu sediaan (Bolton, 2009).

\section{Metode Penelitian}

Alat

Alat yang dipergunakan meliputi : Mixer, Hardness tester (vanguard model YD-1), Friabilator tester (Pharmec), Mesin Tablet Single Punch (Rieckermann Korsch Berlin), Disintegration tester (Erweka G.m.b.h Type Z.T-2), Alat uji disolusi (dissolution tester DT 606, Erweka), Neraca elektrik (Alsep, EX 200 A), Neraca Analitik (Inaba Seissakusho LTD, Tokyo, Japan), Spektrofotometer (UV-Vis Hitachi 150-20 Double beam), penangas air, labu disolusi USP XIX, pengaduk dayung, lemari pengering dan Stopwatch (Heuer), Alat penghisap debu, ayakan mesh 14 dan 16, Mortir dan stamper, serta alat-alat gelas yang biasa digunakan.

Bahan

Bahan yang digunakan dalam penelitian adalah asam mefanamat (Zhejiang Tian Xian Pharmachem.Co., Ltd, RRC) PVP K-29/ 32 (isp Technologis Inc. USA), Avicel PH 101, laktosa (DMV - International Vegel, The Netherlands), talcum (Haichen Talk Powder, RRC), Mg stearat (BP/ USP, PT Asphelia Gracia Pratama), $\mathrm{NaOH}$ (Pro analisa, Merck), $\mathrm{KH}_{2} \mathrm{PO}_{4}$ (pro analia, Merck) dan aquades.

Formula tablet asam mefenamat

Tabel I. Formula tablet asam mefenamat

\begin{tabular}{lccc}
\hline \multicolumn{1}{c}{ Formula } & $\begin{array}{c}\text { F I } \\
(\mathbf{m g})\end{array}$ & $\begin{array}{c}\text { F II } \\
(\mathbf{m g})\end{array}$ & $\begin{array}{c}\text { F III } \\
(\mathbf{m g})\end{array}$ \\
\hline Asam mefenamat & 500 & 500 & 500 \\
Laktosa & 161 & 161 & 161 \\
Avicel PH 101 & 25 & - & 12,5 \\
PVP & - & 25 & 12,5 \\
Mg stearat & 1,4 & 1,4 & 1,4 \\
Talk & 12,6 & 12,6 & 12,6 \\
Bobot tablet & 700 & 700 & 700 \\
\hline
\end{tabular}




\section{Pembuatan granul}

Asam mefanamat dicampur dengan komponen-komponen lainnya kecuali talk dan $\mathrm{Mg}$ stearat. Kemudian dibuat granul dengan penambahan bahan pengikat yaitu larutan PVP atau Avicel PH 101 (sesuai formula). Massa ini kemudian diayak dengan ayakan ukuran 14 mesh, keringkan pada lemari pengering pada suhu $40-60^{\circ} \mathrm{C}$ selama 2 jam. Granul kering diayak dengan ayakan ukuran 16 mesh, lalu uji sifat fisik granul.

\section{Uji sifat fisik granul}

1. Pengujian sifat alir.

Masukkan $20 \mathrm{~g}$ campuran bahan dituang perlahan kedalam pinggir corong yang ujungnya telah ditutup, kemudian permukaan serbuk diratakan. Buka penutup bagian ujung corong biarkan mengalir. Catat waktu yang diperlukan.

2. Uji kompaktibilitas.

Bahan yang akan diuji dimasukkan kedalam ruang cetak dan diratakan, kemudian dikempa. Tablet yang dihasilkan diukur kekerasannya dengan hardness tester.

3. Uji disolusi.

Terhadap granul asam mefanamat hasil masing-masing formula dilakukan uji DE60 menggunakan alat uji disolusi USP XXII pengaduk dayung dengan kecepatan 100 putaran permenit. Massa granul ditimbang $686 \mathrm{mg}$ dimasukkan kedalam kapsul, lalu dimasukkan ke dalam labu uji disolusi yang berisi $900 \mathrm{ml}$ larutan dapar posfat $\mathrm{pH}$ 7,4 dengan suhu $37 \pm 1{ }^{\circ} \mathrm{C}$. Sampel diambil pada menit ke5, 10, 20, 30, 45 dan 60 sebanyak $5 \mathrm{ml}$. Sampel disaring menggunakan membrane $0,45 \mu \mathrm{m}$ dan selanjutnya ditentukan kadar sampel dengan menggunakan spektrofotometer UV pada panjang gelombang $284 \mathrm{~nm}$.

\section{Penentuan profil sifat fisik granul}

Profil sifat fisik campuran bahan dapat ditentukan melalui pendekatan simplex lattice design berdasarkan persamaan

$\mathrm{Y}=\mathrm{a}(\mathrm{A})+\mathrm{b}(\mathrm{B})+\mathrm{ab}(\mathrm{A})(\mathrm{B})$

dimana:

$\mathrm{Y} \quad=$ respon(hasil percobaan)

$\mathrm{A}$ dan $\mathrm{B} \quad=$ kadar dari campuran eksipien, yang jumlahnya selalu 1 bagian (A adalah fraksi Avicel PH 101 ; B adalah fraksi PVP)

$\mathrm{a}, \mathrm{b}, \mathrm{ab}=$ koefisien yang dapat dihitung dari hasil percobaan.

\section{Penentuan formula optimum}

Formula optimum dipilih berdasarkan nilai total respon yang paling besar. Total respon dapat dihitung dengan rumus :
$\mathrm{R}_{\text {total }}=$ (bobot $\mathrm{x} \mathrm{N}$ waktu alir) + (bobot $\mathrm{x} \mathrm{N}$ kompaktibilitas) + (bobot $\times \mathrm{N}$ disolusi) ....(2)

$\mathrm{N}$ merupakan normalitas yang dihitung dengan rumus:

$$
\mathrm{N}=\frac{X-X \min }{X \max -X \min }
$$

Dimana,

$\mathrm{X}=$ respon yang didapat dari percobaan

$\mathrm{Xmin}=$ respon minimal yang diinginkan

$\mathrm{Xmax}=$ respon maksimal yang diinginkan

Formula dengan respon tertinggi dipilih

sebagai formula optimum (Bolton, 2009).

Uji validitas persamaan-persamaan yang didapat

Validasi dilakukan dengan mengevaluasi sifat-sifat fisik granul formula terpilih tersebut. Hasilnya dibandingkan dengan hasil teoritisnya.

Pembuatan tablet dari formula yang terpilih

Asam mefanamat dicampur dengan laktosa dan Avicel PH 101. Kemudian dibuat granul dengan penambahan bahan pengikat yaitu larutan PVP sehingga diperoleh granul basah. Ayak dengan ayakan no. 14. Keringkan, lalu ayak granul kering dengan ayakan no. 16. Kemudian timbang granul kering dan tambahkan bahan pelicin, dan granul siap untuk dicetak dengan berat tablet $700 \mathrm{mg}$ dan kekerasan $5 \mathrm{~kg}$.

Uji sifat fisik tablet formula terpilih

1. Uji keseragaman bobot.

Dua puluh tablet ditimbang satu persatu pada neraca elektrik. Hitung bobot rata-rata, SD dan CVnya.

2. Uji kekerasan tablet.

Dilakukan uji kekerasan tablet satu per satu dengan alat hardness tester.

3. Uji kerapuhan tablet.

Dalam friability tester 20 tablet secara acak dari masing-masing formulasi diputar selama 4 menit. Seluruh tablet setelah dibebaskan dari serbuk-serbuk halus yang menempel, ditimbang sebelum dan sesudah diputar. Kerapuhan = susut berat / berat mula-mula x $100 \%$; memenuhi syarat bila kerapuhan kurang dari $0,8 \%$.

4. Uji waktu hancur tablet.

Masukkan air ke dalam alat, lalu panaskan air tersebut pada suhu $37^{\circ} \mathrm{C} \pm 2^{\circ} \mathrm{C}$, kemudian masukkan 6 tablet (tiap tabung 1 tablet) pada alat penguji waktu hancur (disintegration tester). Hidupkan alat dan stopwatch secara bersamaan. Catat waktu hancur tiap-tiap tablet. (Anonim, 2014)

5. Uji disolusi tablet.

Tablet asam mefanamat hasil dari formula terpilih diuji DE-60 nya menggunakan alat uji disolusi USP XXII pengaduk dayung dengan kecepatan 100 putaran per menit. Masukkan tablet 
kedalam labu uji disolusi yang berisi $950 \mathrm{ml}$ larutan dapar posfat $\mathrm{pH} 7,4$ dengan suhu $37 \pm 1^{\circ} \mathrm{C}$. Sampel diambil pada menit ke 5, 20, 30, 45 dan 60 sebanyak 5,0 ml. Sampel disaring menggunakan saringan 0,45 $\mu \mathrm{m}$ dan selanjutnya ditentukan kadar dengan menggunakan spektrofotometer UV pada panjang gelombang $284 \mathrm{~nm}$.

\section{Analisa Data}

Data kuantitatif yang diperoleh dianalisis secara statistik menggunakan uji-t.

\section{Hasil dan Pembahasan}

Pengujian kualitas granul dilakukan pada granul kering yang telah diayak dengan ayakan no.18. Pemeriksaan ini meliputi waktu alir, kompaktibilitas, dan disolusi, data dapat dilihat pada Tabel II.

Waktu alir merupakan salah satu gambaran sifat alir granul yang mempengaruhi keseragaman jumlah atau volume bahan yang masuk ruang pencetakan tablet. Granul yang memiliki waktu alir yang baik menghasilkan tablet dengan bobot

Tabel II. Hasil uji sifat fisik granul asam mefenamat

\begin{tabular}{cccc}
\hline Sifat Fisik Granul & F1 & F2 & F3 \\
\hline Waktu alir (detik) & $6,90 \pm 0,1$ & $9,27 \pm 0,252$ & $10,97 \pm 0,473$ \\
Kompaktibilitas (kg) & $2,00 \pm 0,608$ & $4,10 \pm 0,306$ & $3,63 \pm 0,351$ \\
Disolusi (DE60) (\%) & $9,69 \pm 0,558$ & $14,60 \pm 0,672$ & $11,56 \pm 0,783$ \\
\hline
\end{tabular}

Keterangan:

$\mathrm{F} 1=100 \%$ Avicel PH101 : $0 \%$ PVP

F2 $\quad=50 \%$ Avicel PH101: $50 \%$ PVP

F3 $=0 \%$ Avicel PH101: $100 \%$

dan dosis yang seragam. Hasil pemeriksaan diatas (Tabel II) menunjukan bahwa Avicel PH101 memiliki waktu alir yang lebih cepat dari pada PVP, hal ini juga berarti bahwa Avicel PH101 memiliki sifat alir yang lebih baik dari pada PVP. Uji kompaktibilitas masa digunakan untuk mengetahui mudah tidaknya granul dikempa menjadi tablet. $\mathrm{Uji}$ kompaktibilitas dilakukan dengan memasukkan granul ke dalam ruang die dengan volume yang sama. Semua formula dikempa dengan tekanan kompresi yang diatur.

\section{Profil Sifat Fisik Granul}

Uji disolusi pada granul asam mefenamat ini dilakukan dengan metode DE60 dengan medium dapar posfat $\mathrm{pH}$ 7,4 dan selanjutnya kadar asam mefenamat ditentukan dengan spektrofotometri UV pada panjang gelombang maksimal yang telah ditentukan sebelumnya yaitu pada $284 \mathrm{~nm}$. Hasil pengukuran di atas (tabel II) menunjukan bahwa PVP memiliki nilai DE60 yang lebih besar dari pada Avicel PH101Uji sifat fisik granul akan menghasilkan profil sifat fisik campuran dari persamaan dan perhitungan berdasarkan simplex lattice design. Profil ini digunakan untuk menentukan formula optimum dilihat dari kualitas granulnya. Hasil uji sifat granul yaitu uji waktu alir, uji kompaktiilitas, dan uji disolusi digunakan untuk menentukan formula optimum.

\section{Uji sifat alir granul asam mefenamat}

Dari hasil uji terhadap waktu alir granul berdasarkan pendekatan simplex lattice design didapatkan persamaan untuk sifat alir yaitu; $Y=6,9(A)+10,97(B)+1,33(A)(B)$

Keterangan :

$\mathrm{Y}=$ Waktu alir (detik)

$\mathrm{A}=$ Proporsi Avicel PH 101

$\mathrm{B}=$ Proporsi PVP

Persamaan diatas menunjukkan bahwa PVP memberikan pengaruh yang lebih besar (nilai koefisien $=10,97)$ terhadap waktu alir dibandingkan dengan Avicel PH 101 (nilai koefisien =6,9), hal ini menunjukan bahwa semakin besar proporsi PVP yang digunakan akan meningkatkan respon waktu alirnya yang berarti memperburuk sifat alirnya. Sebaliknya, semakin besar proporsi Avicel PH101 yang digunakan akan menurunkan respon waktu alir yang berarti memperbaiki sifat alirnya. Dari persamaan tersebut juga dapat diketahui bahwa interaksi antara kedua bahan tersebut juga dapat mempengaruhi respon waktu alirnya (koefisien = 1,33).

Profil waktu alir granul yang diperoleh dari percobaan dengan menggunakan persamaan simplex lattice design, digambarkan pada Gambar 1. Berdasarkan profil tersebut, terlihat bahwa respon waktu alir terkecil terdapat pada proporsi 100\% Avicel PH 101 yang berarti memiliki sifat alir yang paling baik. Sedangkan respon waktu alir yang terburuk terdapat pada proporsi 100\% PVP yaitu lebih dari 10 detik. Sifat alir campuran bahan pengisi Avicel PH 101 dan PVP berada diantara sifat alir masing- masing bahan pengisi yang hanya mengandung Avicel PH 101 dan hanya mengandung PVP. 


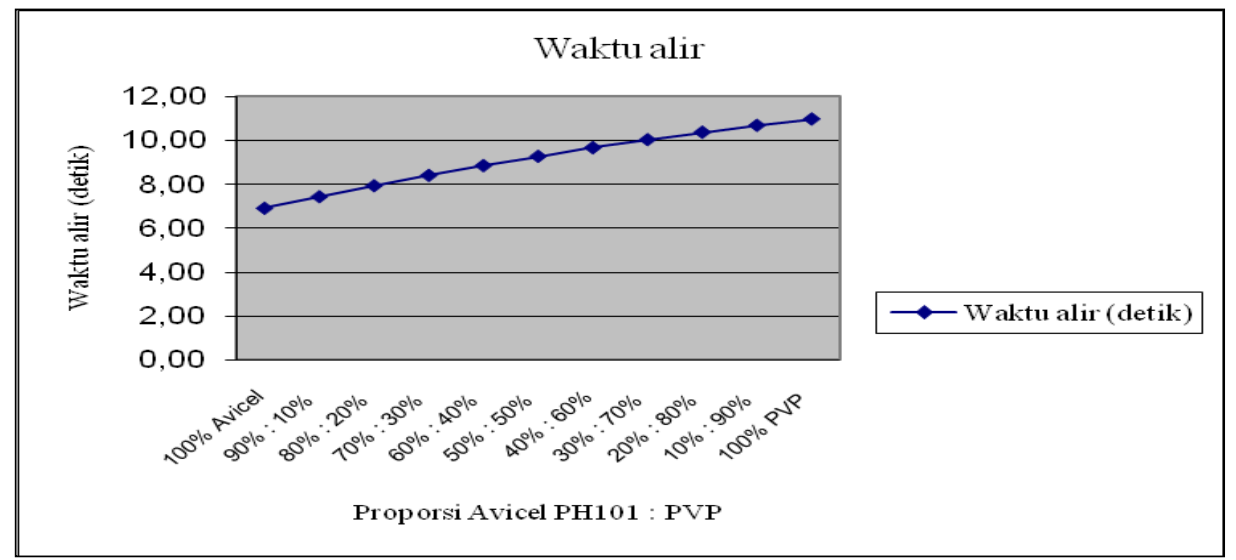

Gambar 1. Profil waktu alir granul asam mefenamat berdasarkan persamaan simplex lattice design

\section{Uji kompaktibilitas granul asam mefenamat}

Dari hasil uji kompaktibilitas diperoleh persamaan berdasarkan pendekatan simplex lattice design didapatkan persamaan untuk kompaktibilitas yaitu;

Keterangan

$$
Y=2(A)+3,63(B)+5,13(A)(B)
$$

$\mathrm{Y}=$ Waktu kompaktibilitas $(\mathrm{kg})$

A $=$ Proporsi Avicel PH 101

$\mathrm{B}=$ Proporsi PVP

Persamaan diatas menunjukkan bahwa PVP (nilai koefisien $=3,6$ ) memberikan pengaruh yang lebih besar terhadap kompaktibilitas dibandingkan dengan Avicel PH 101 (nilai koefisien =2). Interaksi antara kedua bahan tersebut juga memiliki pengaruh yang cukup besar terhadap respon kompaktibilitas granul, yang ditandai dengan nilai koefisien yang cukup besar yaitu 5,13. Nilai koefisien interaksi yang positif dengan nilai yang relative besar bahkan lebih besar dibanding dengan koefisien yang dimiliki oleh masing-masing bahan, berarti bahwa adanya interaksi antara kedua bahan tersebut pada umumnya akan meningkatkan kompaktibilitasnya.

Hasil uji kompaktibilitas granul asam mefenamat dari campuran avicel PH 101 dan PVP berdasarkan persamaan dan perhitungan menggunakan pendekatan simplex lattice design dapat digambarkan sebagai berikut :

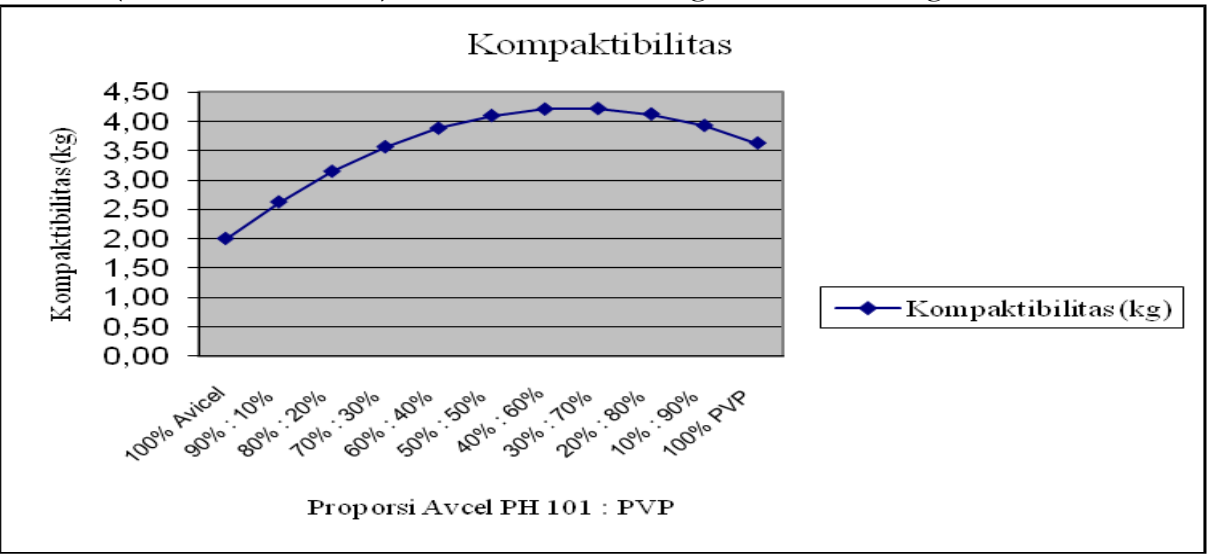

Gambar 2. Profil kompaktibilitas granul asam mefenamat berdasarkan simplex lattice design

\section{Uji disolusi granul asam mefenamat}

Dari hasil uji disolusi (DE60) diperoleh persamaan berdasarkan pendekatan simplex lattice design didapatkan persamaan untuk disolusi yaitu; $Y=9,69(A)+11,56(B)+15,90(A)(B)$
$\mathrm{Y}=$ Disolusi $(\%)$

A $=$ Proporsi Avicel PH 101

$\mathrm{B}=$ Proporsi PVP

Persamaan diatas menunjukkan bahwa PVP (nilai koefisien $=11,56)$ memberikan pengaruh yang lebih besar terhadap disolusi asam mefenamat dibandingkan dengan Avicel PH 101 (nilai koefisien $=9,69$ ). Interaksi antara kedua bahan tersebut juga memiliki pengaruh yang cukup besar terhadap

Keterangan : 
respon disolusi asam mefenamat, yang ditandai dengan nilai koefisien yang tergolong besar yaitu 15,90. Nilai koefisien interaksi yang positif dengan nilai yang relative besar bahkan lebih besar dibanding dengan koefisien yang dimiliki oleh masing-masing bahan, berarti bahwa adanya interaksi antara kedua bahan tersebut pada umumnya akan meningkatkan disolusinya.
Hasil uji disolusi granul asam mefenamat dari campuran avicel PH 101 dan PVP berdasarkan persamaan dan perhitungan menggunakan pendekatan simplex lattice design dapat digambarkan sebagai berikut :

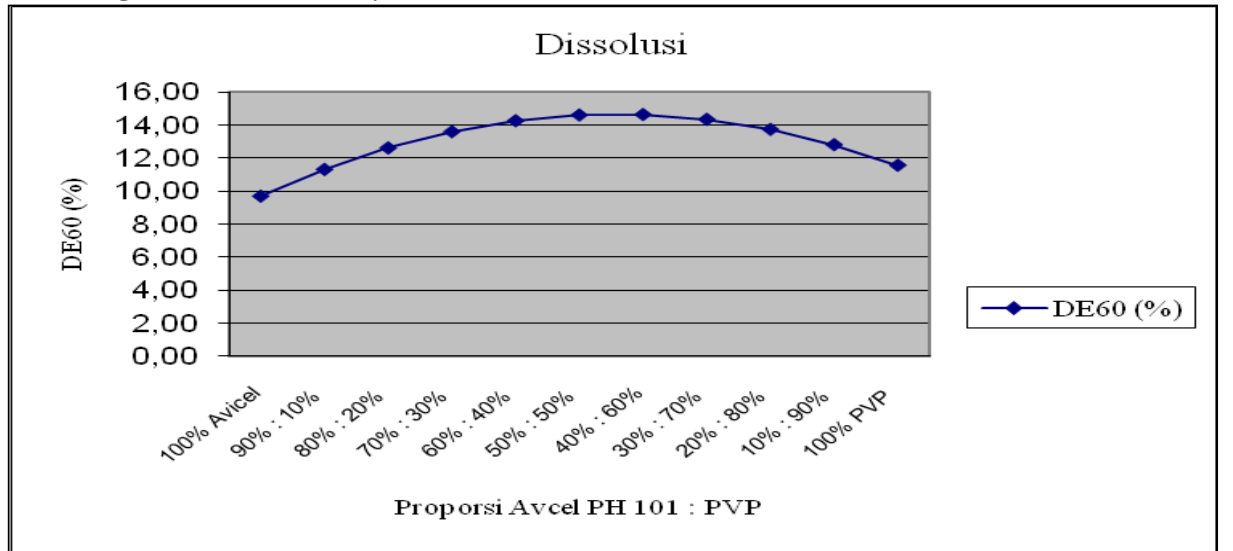

Gambar 3. Profil disolusi granul asam mefenamat berdasarkan simplex lattice design

Gambar 3 menunjukkan bahwa respon disolusi (DE) terbaik terdapat pada proporsi 40\% Avicel PH101 : 60\% PVP. Sedangkan respon disolusi yang terburuk dimiliki oleh proporsi 100\% Avicel PH 101. Dari gambar tersebut juga dapat diketahui bahwa penambahan proporsi PVP, pada umumnya dapat meningkatkan respon disolusinya.

\section{Penentuan Formula Optimum}

Formula optimum diperoleh dari respon total yang paling besar, yang dapat dilihat pada tabel III.

Tabel III. penentuan formula optimum

\begin{tabular}{|c|c|c|c|c|c|c|c|c|c|c|}
\hline \multirow{2}{*}{ PROPORSI } & \multicolumn{3}{|c|}{$\mathbf{Y}$} & \multicolumn{3}{|c|}{$\mathbf{N}$} & \multicolumn{3}{|c|}{ NP } & \multirow[t]{2}{*}{ RTOT } \\
\hline & WA & CMPAC & DIS & WA & CMPAC & DIS & WA & CMPAC & DIS & \\
\hline $100 \% \mathrm{~A}$ & 6,90 & 2,00 & 9,69 & 0,2250 & 0,5000 & 0,1150 & 0,0900 & 0,1500 & 0,0345 & 0,2745 \\
\hline $90 \% \mathrm{~A}: 10 \% \mathrm{~B}$ & 7,43 & 2,62 & 11,31 & 0,3567 & 0,3438 & 0,3846 & 0,1427 & 0,1031 & 0,1154 & 0,3612 \\
\hline $80 \% \mathrm{~A}: 20 \% \mathrm{~B}$ & 7,93 & 3,15 & 12,61 & 0,4818 & 0,2133 & 0,6012 & 0,1927 & 0,0640 & 0,1804 & 0,4371 \\
\hline $70 \% \mathrm{~A}: 30 \% \mathrm{~B}$ & 8,40 & 3,57 & 13,59 & 0,6002 & 0,1084 & 0,7648 & 0,2401 & 0,0325 & 0,2294 & 0,5021 \\
\hline $60 \% \mathrm{~A}: 40 \% \mathrm{~B}$ & 8,85 & 3,88 & 14,25 & 0,7120 & 0,0292 & 0,8754 & 0,2848 & 0,0088 & 0,2626 & 0,5562 \\
\hline $50 \%$ A : $50 \%$ B & 9,27 & 4,10 & 14,60 & 0,8171 & 0,0244 & 0,9330 & 0,3268 & 0,0073 & 0,2799 & 0,6140 \\
\hline $40 \% \mathrm{~A}: 60 \% \mathrm{~B}$ & 9,66 & 4,21 & 14,63 & 0,9155 & 0,0523 & 0,9376 & 0,3662 & 0,0157 & 0,2813 & 0,6632 \\
\hline $30 \% \mathrm{~A}: 70 \% \mathrm{~B}$ & 10,03 & 4,22 & 14,34 & 1,0072 & 0,0546 & 0,8892 & 0,4029 & 0,0164 & 0,2668 & 0,6860 \\
\hline $20 \%$ A : $80 \%$ B & 10,37 & 4,12 & 13,73 & 1,0923 & 0,0312 & 0,7878 & 0,4369 & 0,0094 & 0,2363 & 0,6826 \\
\hline $10 \% \mathrm{~A}: 90 \% \mathrm{~B}$ & 10,68 & 3,93 & 12,80 & 1,1707 & 0,0178 & 0,6334 & 0,4683 & 0,0053 & 0,1900 & 0,6637 \\
\hline $100 \% \mathrm{~B}$ & 10,97 & 3,63 & 11,56 & 1,2425 & 0,0925 & 0,4260 & 0,4970 & 0,0278 & 0,1278 & 0,6526 \\
\hline
\end{tabular}

Keterangan:

$$
\begin{array}{ll}
\text { WA } & =\text { waktu alir } \\
\text { CMPC } & =\text { kompaktibilitas } \\
\text { DIS } & =\text { disolusi }
\end{array}
$$

Hasil perhitungan pada tabel III diketahui bahwa campuran Avicel PH 101-PVP dengan perbandingan 30\%: $70 \%$ memiliki respon total tertinggi yaitu 0,686. Formula optimum di atas merupakan formula prediksi atau teoritis, oleh karena itu penelitian dilanjutkan dengan membandingkan formula optimum prediksi dengan hasil praktik sesungguhnya

\section{Sifat Fisik Granul Formula Optimum}

Hasil uji sifat fisik formula optimum dengan respon total tertinggi yaitu pada komposisi 30\% Avicel PH 101 : 70\% PVP dapat dilihat pada tabel IV. 
Tabel IV. Hasil uji sifat fisik granul formula optimum

\begin{tabular}{cccc}
\hline Sifat Fisik Granul & $\begin{array}{c}\text { Waktu alir } \\
(\text { detik) } \pm \text { SD }\end{array}$ & $\begin{array}{c}\text { Kimpaktibilitas } \\
(\mathrm{kg}) \pm \text { SD }\end{array}$ & $\begin{array}{c}\text { Disolusi (DE60) (\%) } \\
\pm \text { SD }\end{array}$ \\
\hline $30 \%$ Avicel PH 101: $70 \%$ PVP & $9,9 \pm 0,173$ & $4,07 \pm 0,404$ & $14,89 \pm 0,937$ \\
\hline
\end{tabular}

Hasil penelitian pada tabel IV menunjukkan bahwa sifat fisik dari formula dengan perbandingan 30\% Avicel PH 101 : 70\% PVP yang diuji menunjukkan hasil yang baik. Selanjutnya hasil percobaan ini dibandingkan dengan hasil uji secara teoritis yang diperoleh melalui pendekatan simplex lattice design sebelumnya, untuk membuktikan apakah pendekatan tersebut sesuai dengan hasil yang diperoleh dari percobaan langsung.

Untuk membandingkan antara formula optimum prediksi dengan tercoba dapat dilakukan secara statistik dengan uji $t$ sampel tunggal $(t-$ Test $)$.

Hasil pengujian, menunjukan bahwa nilai signifikasi formula optimum hasil prediksi dan hasil percobaan lebih besar dari 0,05 sehingga Ho diterima, bahwa waktu alir, kompaktibilitas dan disolusi (DE60) granul antara formula optimum hasil prediksi dan hasil percobaan tidak berbeda signifikan.

\section{Sifat Fisik Tablet Formula Optimum}

Uji sifat fisik tablet asam mefenamat meliputi keseragaman bobot, kekerasan, kerapuhan, waktu hancur dan disolusi.

Tabel V. Sifat fisik tablet asam mefenamat formula optimum

\begin{tabular}{cc}
\hline Sifat fisik tablet & Formula optimum \\
\hline Keseragaman bobot & $699,55 \pm 8,1659(\mathrm{CV}: 1,17 \%)$ \\
Kekerasan (kg) & $7 \pm 0,2345$ \\
Kerapuhan (\%) & $0,78 \pm 0,0642$ \\
Waktu hancur (menit) & $13 \pm 0,5874$ \\
Disolusi (DE60) (\%) & $10,43 \pm 0,4751$ \\
\hline
\end{tabular}

Pada tabel $\mathrm{V}$ dapat diketahui bahwa tablet asam mefenamat formula optimum (Avicel PH $10130 \%$ : PVP $70 \%$ ) memenuhi persyaratan tablet yang baik.

\section{Simpulan}

Campuran bahan dengan proporsi Avicel PH $10130 \%$ dan PVP $70 \%$ memberikan hasil optimal pada sifat fisik granul dan menghasilkan tablet asam mefenamat yang memenuhi persyaratan.

\section{Ucapan Terima Kasih}

Penulis mengucapkan terima kasih kepada keluarga dan semua pihak yang memberikan dukungan kepada penulis untuk menyusun dan menyelesaikan penelitian ini.

\section{Daftar Pustaka}

[Anonim]. 2014. Farmakope Indonesia Edisi V. Jakarta: Departemen Kesehatan Republik Indonesia. hlm 156-159, 1526, 1631,1605.

Adam A, Schrimpl L, Schmidt PC., 2000. Factors influencing capping and cracking of mefenamic_acid tablets. Dalam Drug Dev Ind Pharm 26(5), Department of Pharmaceutical Technology, Eberhard-Karls-University Tübingen, Germany., hal 477-487.

Bolton, S., 2009, Pharmacentical Statistics: Practical and Clinical Applications, Fifth ed. Marcel Dekker. Ink., New York. hlm 439.

Folttmann dan Quadir, 2008, Polyvinylpirrolidone(PVP)-One of the Most Widely Used Excipient in Pharmaceutical: An Overview, Drug Delivery Technology Vol 8 No 6, pp. 22-27.

Goeswin, Agoes. 2008. Pengembangan Sediaan Farmasi. Bandung: IPB. hlm 86.

Kibbe A.H., 2009, Povidone, Dalam Rowe, R. C., Sheskey, P. J., Quinn, M. E.(Eds). Handbook of Pharmaceutical Excipients, Pharmaceutical Press and American Pharmacists Association, London, hlm 581-585.

Rowe, R. C., Sheskey, P. J., and Weller, P. J., 2009, Handbook of Pharmacentical Excipients Sixth Edition, Pharmaceutical Press, London. hlm 131 